\title{
BMJ Open Facilitators and barriers to participation of private sector health facilities in government-led schemes for maternity services in India: a qualitative study
}

To cite: Yadav V, Kumar S, Balasubramaniam S, et al. Facilitators and barriers to participation of private sector health facilities in government-led schemes for maternity services in India: a qualitative study. BMJ Open 2017;7:e017092. doi:10.1136/ bmjopen-2017-017092

Received 30 March 2017 Accepted 12 April 2017

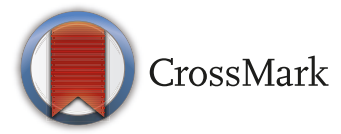

${ }^{1}$ Jhpiego - an affiliate of Johns Hopkins University, New Delhi, India

${ }^{2}$ Jhpiego - an affiliate of Johns Hopkins University, Ranchi, Jharkhand

${ }^{3}$ Jhpiego - an affiliate of Johns Hopkins University, Lucknow, UP

Correspondence to

Dr. Ashish Srivastava; asheishsrivastava@gmail.com Ashish.Srivastava1@Jhpiego. org

\section{ABSTRACT}

Objective Despite provision of accreditation of private sector health providers in government-led schemes for maternity services in India, their participation has been low. This has led to an underutilisation of their presence, resources and expertise for providing quality maternal and newborn health services. This study explores the perception of various stakeholders on expectations, benefits, barriers and facilitators to private sector participation in government-led schemes-specifically Janani Suraksha Yojana (JSY)—for maternity service delivery.

Design Narrative-based qualitative study. Face-to-face indepth interviews were conducted with study participants. The interviews were transcribed, translated and analysed using a reflexive and inductive approach to allow codes, categories and themes to emerge from within the data. Setting Private obstetricians, government health officials and FOGSI (Federation of Obstetrics and Gynaecological Societies of India) members, Jharkhand and Uttar Pradesh, India.

Participants Eighteen purposefully selected private obstetricians from 9 cities across states of Uttar Pradesh and Jharkhand, 11 government health officials and 2 FOGSI members.

Results The major factors serving as barriers to participation of private practitioners in JSY — which emerged on thematic analysis-were low reimbursement amounts, delayed reimbursements, process of interaction with the government and administrative issues, previous experiences and trust deficit, lack of clarity on the accreditation process and patient-level barriers. On the other hand, factors which were facilitators to participation of private practitioners were ease of process, better communication, branding, motivation of increasing clientele as well as satisfaction of doing social service.

Conclusion Factors such as financial processes and administrative delays, mistrust between the stakeholders, ambiguity in processes, lack of transparency and lack of ease in the process of empanelment of private sector are hindering effective public-private partnerships under JSY. Simplifying and strengthening the processes, communication strategies and branding can help revitalise it.
Strengths and limitations of this study

- Perspectives of both private practitioners and government officials responsible for managing public-private partnership were studied which gave a holistic view of major challenges in the system for effective partnership between public and private sectors and possible solutions to them.

- Study was part of a larger programme to improve quality of care in private sector health institutions of two states and thus pre-existing working relationships helped us elicit more candid responses from the study participants.

- Study was conducted in states of Uttar Pradesh and Jharkhand that are most relevant to this issue by virtue of their need for partnering with private practitioners due to large size of population to be catered and issues of access respectively.

- Perceptions of private practitioners from other parts of the country were not taken.

- Private practitioners who were interviewed were those who were practising in urban and periurban areas and those practising in rural areas were not included as they were not involved in the project.

\section{INTRODUCTION}

India has one of the most privatised medical systems in the world with private sector catering to $80 \%$ of outpatient care and up to $60 \%$ of inpatient care in the country. ${ }^{1}$ Up to $60 \%$ of total hospital bed strength and majority of human resources- $-70 \%$ of total health workforce, $80 \%$ of physicians and almost all of the 30000 obstetricians in India are serving in the private sector. ${ }^{12}$ This indicates a strong potential for this sector to contribute to childbirth care-a priority area for India.

However, private sector is underutilised for this purpose. As per a recent estimate, up to $30 \%$ of institutional deliveries in rural areas and up to $52.5 \%$ of institutional deliveries in 
urban areas are happening in the private sector. ${ }^{3}$ Subanalysis of these data reveals that there is a fair appetite for seeking maternity care at private facilities among various socioeconomic strata (ranges from $15.5 \%$ to $51.2 \%$ women in wealth quintile class 1 to 5 in rural areas and $31.9 \%$ to $80.4 \%$ women in quintile class 1 to 5 in urban areas). ${ }^{3}$ This indicates two major considerations for private sector engagement for maternity care in Indiaexploring mechanisms to leverage the presence of private sector to complement public sector in areas where it is inadequate, and ensuring that clients, especially of lower wealth quintiles, accessing services at private facilities of their choice are financially protected and receive good quality care.

The policy for accreditation and empanelment under government's flagship programme, the National Health Mission (NHM), offers opportunities for both leveraging private sector presence and ensuring financial and clinical protection of pregnant women seeking care at private facilities. Janani Suraksha Yojana (JSY), under NHM, is a conditional cash transfer scheme covering the whole country. In 10 select high-focus states, the scheme targets all pregnant women delivering at health facilities with entitlement to cash transfers after delivery. ${ }^{4}$ To improve the reach and quality of the services, it has a provision for partnerships with private sector with two main modes-a cost reimbursement model where private health facilities meeting a certain set of criteria are accredited and empanelled in JSY and render free care during childbirth in lieu of reimbursement provided by the government; and a contracting-in model where specialists from private facilities are contracted on a case basis to provide care for cases needing specialist attention such as a caesarean section (C-section). ${ }^{56}$ Based on the need, district health officials are expected to approach the available and eligible private maternity facilities for empanelment under this scheme. Empanelled facilities are expected to provide free care for childbirth and they can then get the costs incurred reimbursed from the district health department. This reimbursement is based on submission of documentary evidence of care provided to the clients. Usually, these facilities are reimbursed after they have completed care for a batch of beneficiaries rather than reimbursement on an individual case basis. This provision is in line with India's previous National Health Policy $^{7}$ and recently released National Health Policy ${ }^{8}$ which clearly stress the importance of public-private partnerships (PPPs) in formulation and implementation of health and family welfare policies and programmes at both national and state levels. ${ }^{78}$

With the initiation of NHM, almost all states in India initiated accreditation of private practitioners under JSY or other specific programmes under NHM for ensuring high-quality care during childbirth which is affordable and accessible. A similar PPP programme called Chiranjeevi Yojana (CY) was introduced in Gujarat with the primary objective of increasing institutional births and reducing out-of-pocket expenditure among below poverty line and tribal pregnant women through empanelment of private practitioners. It was considerably studied and initially recognised as a successful scheme. ${ }^{910}$ An urban area-focused example was the Mamta scheme implemented in the National Capital Territory of India, where private facilities were empanelled in government system to increase access to high-quality care among pregnant women in urban slums. ${ }^{11}$

However, PPPs for maternity services did not achieve desired success. Later evaluations of effectiveness of the CY found no effect on institutional delivery rates, mortality and out-of-pocket expenditures. ${ }^{12}$ A concurrent assessment of JSY in selected states by Unicef showed that only $36.6 \%$ of the interviewed women were aware of empanelled private hospitals and only $1.4 \%$ of the beneficiaries availed services from them. ${ }^{13}$ Another evaluation of JSY found that partnership with private sector facilities under JSY was very poor in states that were considered high focus by government of India based on their maternal and newborn health indicators. ${ }^{5}$ An evaluation of Mamta scheme showed a potential for increasing institutional delivery rates, but the scheme remained unattractive for private practitioners and many targeted beneficiaries still remained outside the ambit of services. ${ }^{14}$ Factors such as the concentration of private practitioners in urban areas leading to inadequate use, selection of uncomplicated cases by empanelled practitioners and poor knowledge among beneficiaries regarding free availability of services at these sites were cited as major reasons for suboptimal performance of these schemes. ${ }^{15}$

These findings brought the growing belief that while private sector engagement is desirable to complement the public sector, its current distribution makes it difficult to address specific needs for socially and geographically marginalised communities. Accordingly, efforts to empanel private health facilities under NHM slackened in most of the states. Recent reports indicate that most of the NHM's high-focus states have a very low number of private sector facilities empanelled under JSY. ${ }^{16}$

However, the role of private sector in maternity care in India cannot be fully discounted on account of these initial setbacks. Private sector, even with its urban area affinity, can play a significant role in decongesting the tertiary care facilities of the basic obstetric care. Analysing the available Health Management Information System (HMIS) data from all the states in India, we identified that District Hospital, the only tertiary care public health facility in a district, alone handles up to $45 \%$ of total deliveries happening in a district. ${ }^{17}$ Overburdening of public sector facilities leads to poor work management resulting in a quality gap. Experience from programme evaluations of public sector facilities also indicates that the quality of care at public health institutions currently providing delivery services is a challenge. ${ }^{5}$ This quality gap is also evident from the fact that despite multifold improvement in institutional delivery rates, proportional reduction in maternal and newborn mortality has not been witnessed. ${ }^{16-22}$ 
Table 1 Distribution of study participants across states and categories.

\begin{tabular}{lll}
\hline Participant & $\begin{array}{l}\text { Uttar Pradesh } \\
\text { (number of } \\
\text { interviews) }\end{array}$ & $\begin{array}{l}\text { Jharkhand } \\
\text { (number of } \\
\text { interviews) }\end{array}$ \\
\hline Private practitioners & 10 & 8 \\
$\begin{array}{l}\text { District health officials } \\
\text { State health officials }\end{array}$ & 2 & 2 \\
$\begin{array}{l}\text { Central government } \\
\text { officials }\end{array}$ & 1 \\
FOGSI members & 3 \\
\hline
\end{tabular}

FOGSI, Federation of Obstetrics and Gynaecological Societies of India.

Potential usefulness of private sector in sharing burden with the public sector to improve efficiency and quality has been reported from other health programmes, such as improving vaccine coverage, improving availability of drugs like insulin in the market and improving tuberculosis (TB) care in Indian setting. ${ }^{23-25}$

Another important area where private sector can play an important role in is filling the specialist availability gap in public sector. Public sector suffers from a severe shortage of obstetric specialists at all levels of health facilities. ${ }^{16}$ In most instances, complicated cases from within a district are eventually supposed to be managed at already overburdened and resource-constrained district hospital level or beyond facilities situated in urban areas. In such cases, free transportation to the pregnant women and their newborns is permissible under the ambit of Janani Shishu Suraksha Karyakram launched in 2011. ${ }^{26}$ Since pregnant women are referred to these institutions, in case of specialist shortage, emergency obstetric care (EmOC) services can be provided in private sector facilities empanelled under JSY scheme. A study on PPP for EmOC in Maharashtra found that PPPs under JSY for this purpose were inadequate and the administrators preferred a cost subsidisation of services in private sector over hiring a specialist on contract for provision of services in public facilities. ${ }^{6}$

Providing high-quality care to its existing users is another significant way by which the private sector can contribute to the overall improvement in maternity services in the country. Recent studies in India found concerns with quality of services in private sector maternity institutes. ${ }^{27} 28$ Since empanelment schemes also require participating facilities to adhere to prescribed norms for inclusion and sustained participation, accreditation of private facilities also has the potential for standardisation of quality of services for their existing clients of maternity services.

Jhpiego-an international not-for-profit health organisation working in the field of women's healthimplemented a programme for quality improvement for maternity services in private sector facilities in the states of Uttar Pradesh (UP) and Jharkhand. Most of the targeted facilities were in urban and periurban areas in tier 2 and below cities and were led by trained obstetricians. As a part of our efforts to strengthen overall maternal health quality by leveraging the private sector presence, we learnt that these private facilities, if empanelled with the government's JSY scheme, can contribute significantly to the decongestion of public institutions and filling the specialist availability gap in public sector while benefiting from a broader base of clients through this scheme. However, upon engaging with private practitioners, we found that though they were interested in partnering with government programmes, there were multiple influencers of their engagement with government schemes. Considering this, we designed this study to understand the barriers to the engagement of private practitioners situated in urban areas with government schemes. For perceived barriers, we also explored potential solutions with relevant stakeholders and present them for the consideration of programme implementers in similar settings. In addition, we also included understanding the perspective of government officials in empanelling these reputed private facilities for complementing public sector as a key objective of the study.

\section{METHODS}

This was a narrative-based qualitative study conducted between September and November 2014. This study was part of a larger project of Jhpiego implemented with the support of MSD for Mothers. .

The study involved two groups of stakeholders: the government officials from central government and state governments of Jharkhand and UP as well as the private practitioners and members of Federation of Obstetrics and Gynaecological Societies of India (FOGSI). FOGSI is a professional organisation representing practitioners of obstetrics and gynaecology in India. The private practitioners were selected by purposive sampling with maximum variation in terms of their involvement with government empanelment schemes, their work experience, their location (across the two states of UP and Jharkhand), average number of deliveries conducted per month at their facilities and their type of practice-whether individual practice or a combined practice like in multispecialty hospitals. Only private practitioners from facilities conducting more than 25 deliveries per month on an average were approached. These practitioners were from cities of Ranchi, Giridih, Dhanbad and Bokaro in Jharkhand and cities of Meerut, Lucknow, Kanpur, Varanasi and Allahabad in UP. Government officials who were working in maternal health and were involved with the empanelment process were approached. These officials were holding key positions and handling PPPs at district, state and national levels. Two seniorlevel FOGSI members were also approached. Initially, the potential participants were approached over 
telephone and informed about the study. Those who expressed interest were requested for an appointment. On obtaining the appointment, study team members who were to conduct the in-depth interviews visited them and explained the study and its purpose. If they agreed to participate, a written informed consent was obtained and they were interviewed. None of the potential participants who were approached refused to participate. Before initiating the interviews, the interviewers made some general conversation with the participants to make them comfortable and build a rapport.

Study team members who conducted the interviews were public health professionals with prior experience of conducting in-depth interviews and were fluent in participants' native language. They used a pretested, semistructured interview guide for conducting the interviews. The questions were exploratory to allow perceptions and experiences of participants to emerge during the interview. The interviews were conducted after ensuring privacy and confidentiality so that participants were able to speak freely about various issues that were discussed. For all the private practitioners and FOGSI members, the interviews were held in their clinics whereas for all the government officials, the interviews were held in their office cabins. All interviews were audio-recorded. On an average, the interviews took $40 \mathrm{~min}$ each. The study interviews were stopped when we reached response saturation, that is, when no new information was derived through them. A total of 31 interviews were conducted, with 18 of them being with private practitioners from various cities of UP and Jharkhand, 11 with government officials at various levels and 2 with key informants from FOGSI (Table 1).

We hired a qualitative research expert who transcribed and translated the interviews from local language Hindi to English. A member of the study team, who was involved in conducting the interviews, cross-checked each of the transcripts against the original recordings to ensure quality. The qualitative research expert coded the translated transcripts using the software package Atlas.ti V.7.2, using a reflexive and inductive approach to allow codes and categories to emerge from within the data. No pre-existing structural framework was used and a process of constant comparison was carried out between the various categories that emerged across different stakeholders to come up with a list of themes. Once the themes were generated, they were shared with the study team members and consensus on the final list of themes was reached.

Illustrative quotations in English have been used in the results. Both the main project as well as this study received ethical approval from the Institutional Review Boards of International Institute of Health Management Research, India, and Johns Hopkins Bloomberg School of Public Health, USA.
RESULTS

\section{Profile of the participants}

Out of the total 31 participants interviewed, there were 18 private practitioners. All of these respondents had postgraduate training in obstetrics and gynaecology except one who was a medical graduate. All of the respondents' practices were located in tier 2 or below towns in UP and Jharkhand. In most cases, these were just obstetrics and gynaecology practices, but some of them were part of hospitals providing care in other specialties also. Most of these respondents had a practice of more than 15 years with an exception of two respondents who had 5-7years of practice. Most of the respondents reported a mix of clients from urban and rural areas. Out of the 18 private practitioners, 9 reported having been empanelled under the JSY scheme at any point of time. Also, eight reported having been empanelled under Rogi Swasthya Bima Yojana (RSBY) at any point of time. RSBY is a social health insurance scheme implemented by government of India to reduce out-of-pocket expenditure on health and increase access to health. This scheme covers overall health as compared with just the maternity focus under JSY and includes empanelment of private practitioners by private insurance companies to cover below poverty line beneficiaries. $^{29}$

Government officials interviewed represented all three important levels of programme implementation in India-district, state and national levels. State and national officials were responsible for overseeing the larger maternal health and family planning programmes including the PPP components and officials at district level were responsible for actual empanelment of private practitioners.

FOGSI representatives were senior members located at national and state levels who are widely respected among FOGSI members.

\section{General perception of study participants on accreditation and empanelment programmes}

Both government officials and private practitioners felt that it was desirable for private practitioners to engage with such schemes for improving access of quality health services to those who would otherwise not be able to afford them. Government officials also pointed that such schemes had the benefit of using the existing resources of private sector to fill the gaps in government services.

"If we [government/district health officials] can involve them [private practitioners] in accreditation with the government, then we can improve our institutional delivery percentage."

\section{—District health official, UP}

"As far as the private sector is concerned they have resources, specialists...they have really skilled people and we can make use of that."

—District health official, UP 
Expectations from accreditation and empanelment schemes

In addition to their motivation to increase access, government officials emphasised that they expected accredited private practitioners to provide good quality care, especially to the poor patients who avail their services under such schemes.

"Expectation of the government in this regard is mainly to provide ... quality of care especially to below poverty line families, beneficiaries...for better care for normal deliveries, or caesarean sections accessible to them in the nearby areas in private facilities."

—Government official, UP

When asked about their motivations, private practitioners provided the following reasons:

1. To increase their clientele which would happen with the additional numbers of people who come to their facilities through the schemes;

2. To earn more revenues as a result of the increased number of clients especially when high volumes were involved;

3. For public health reasons since participation in such schemes meant that the poor would be able to access their services that would otherwise be out of reach for them;

4. Some private practitioners also felt that being accredited and empanelled under such schemes gave them added legitimacy since being accredited by the government was seen as an added seal of approval for their particular institution and the services they offered.

"One is social service, second is increase the clientele, third is earn money, basic three, every nursing home has these three."

\section{-Private practitioner, UP}

"Number one is of course business...because we are in practice and we want business also, that more footfalls will be there. And number 2 also that we know that these patients they are not going to give business to us. This is a sort of a help or a charity or something giving to the society which is given to the society which is not possible routinely for us."

\section{-Private practitioner, UP}

\section{Previous experiences with accreditation under JSY scheme}

Government officials reported their experience in empanelling private practitioners under JSY scheme. They pointed out that where private participation had worked, the reach of programme, especially in areas where government was not in a position to increase their coverage, had improved.

While private practitioners were motivated and keen to fulfil their obligations under the programmes, most did not have positive experiences to relate to. Practitioners who did not have direct experience described their own and their colleagues' experiences of trying to work with the programme and then opting out since in their opinion, being part of such programmes was not proving to be of any benefit to them in the long run.

"For Maternal health I have been accredited to one programme Janani Suraksha Yojana and frankly I am not finding it to be good."

\section{-Private practitioner, UP}

"I knew of a doctor couple who were involved in the JSY scheme but they finally left it. They said there were lot of problems...payments were not done properly, they were questioned about the treatments they used especially medicines etc. They tried for $3-4$ months and then they said its not functioning smoothly, there is a lot of tension."

-Private practitioner, UP

Government officials at all levels were aware of the fact that enthusiasm of private practitioners and institutions to join their accreditation schemes was not very high and many were avoiding such programmes due to a variety of reasons.

"Some of our schemes are failing badly...the bills are lying around without being paid and the hospitals start refusing saying we will not give any more services to your beneficiaries. So that is a big problem for the government."

-Senior government official, Ministry of Health

"Most of the private practitioners here are not interested in collaborating with the government sector because of the amount of paper work and other types of formalities and also the expectation of the beneficiaries I think."

\section{—District health official, UP}

\section{Barriers to accreditation and empanelment of private practitionerss under JSY scheme}

Further exploration of participant's perspectives on why the scheme was failing to sustain the targeted PPP provided useful information on challenges related to the scheme. From the thematic analysis of the interviews of study participants, the following key barriers to empanelment of private practitioners in government schemes for maternal health emerged:

1. system-level barriers,

2. trust deficit and unpleasant previous experiences,

3. client-level or patient-level barriers, and

4. facility-level barriers.

\section{System-level barriers}

System-level barriers on further analysis yielded subthemes of finance-related barriers as well as barriers related to administrative processes

\section{Finance-related barriers}

Low reimbursement amount was universally referred to as the most important barrier in the present programme. While some participants had been empanelled and knew exact amounts offered under the scheme, others 
had heard from their peers about the reimbursement amounts. Participants mentioned that they were offered 1400-1500 rupees for each successful normal delivery and 4000-6000 rupees for a C-section under the scheme, whereas they charged anywhere between 4000 and 6000 rupees for normal delivery and between 10000 and 12 000 rupees for C-section from their existing clients. In the opinion of private practitioners, the amounts that were reimbursed in return of their services were unrealistic given the costs involved in conducting deliveries at their institutions. They felt that the government officials failed to understand the associated costs such as hospitalisation, medication, and so on, which vary from case to case. As a result of this, many private practitioners ended up suffering losses and in a few years left the programme.

"Is it possible to conduct complicated deliveries at Rs 1500/-? I don't know the people who made this programme what they were taught. I don't know." -Private practitioner, UP

"See the package I am charging others is Rs10,000/for a C-section, so if we do a C-section for Rs. 4000/then where will we get the rest of the money? We cannot send the patient home [discharge] in 3 days right?"

-Private practitioner, Jharkhand

All government officials, except one, also concurred with the assessment that present reimbursement amounts were very low and expecting private practitioners to provide services with such low reimbursement amounts was not sustainable.

"The amount [reimbursement amounts] they get is not really useful. It does not cover whatever services they are providing."

$$
\text { -A government official }
$$

"Charges [reimbursement amounts] are very low. We are giving Rs1500/- for a caesarean and patients give more than this in a normal delivery. So why will they be interested in such a low amount?"

$$
\text { —District health official, UP }
$$

Having to provide services at rates that did not even cover the expenses meant that there were instances of private practitioners charging patients who came to their institutions for some of the services they provided in order to break even. This practice was considered corrupt and frowned upon by government officials and, in their opinion, led to the failure of accreditation schemes in some places.

"They [private practitioners] were taking money from both sides. Not just the government but the clients too. So the scheme failed."

—District health official, UP

"Some hospitals take money to cover their expenses but this is not a healthy thing."

-Private practitioner, UP
Barriers related to administrative processes

The following subthemes emerged on further analysis of barriers related to administrative processes.

\section{Delayed reimbursements}

The amount of time taken to reimburse private practitioners for their services to the patients was another disincentive for private health facilities to participate. Private practitioners with experience of participation in the scheme narrated their personal experience of having to wait for very long time once all formalities were completed.

"Everyone wonders about the delay. Why there is a delay in spite of doing our work well and sending the necessary reports on time. Well even if you say it will be delayed its ok to take 15 days' time. But after that we expect our payments to happen. Otherwise it becomes very difficult for us to run the hospital."

-Private practitioner, Jharkhand

State-level and national-level government officials agreed that the time taken for settlement of claims was not ideal and this was proving to be a stumbling block for private sector participation in empanelment programmes.

"See one of the major problems why the private practitioners do not come and enter into agreements with the government is the release of money. See for example today I might have seen 100 cases. But when the bills are raised he [private practitioner] has no clue if he will get his payment in a month or in two months. Why should I have an MoU with the government when if today I give my services my money will be released in 6 months."

-Senior government official

District-level government officials spoke about addressing delays and pointed out that they were trying out online transfer of money directly to the private practitioners to reduce such delays.

"If they [private practitioners] give us a voucher [reimbursement claim] it is done within 10 days, within even a week because we are now giving the money via RTGS [Real Time Gross Settlement].”

\section{-District health official, UP}

However, one district-level official also pointed out that the delays were due to the way funds were given from the state to the lower levels. He pointed out that without a continuous flow of funds, even when all the documents were submitted by private practitioners, he was unable to reimburse them until the next instalment of funds was released to his office.

"The flow of budget from the state is not continuous, 3 months, 6 months. Suppose the private sector has produced a voucher [reimbursement clain] it will be pending if we do not have money until we receive it from the top." 
Thus even if the transfer was done online, cutting through the delay of preparing and presenting cheques, it did not address the issue of lack of continuous flow of funds.

\section{Process of interaction with the government and administrative issues}

Private practitioners having previous experience of empanelment under a government scheme perceived that they were not made fully aware of the procedure and necessary documentation for empanelment and submission of claims for reimbursement during their engagement. Moreover, they mentioned that government officials were very rigid on the type of documentary proofs of services. Thus, this lack of clarity on necessary submissions on their part and rigidity to evidence on official's part led to multiple submissions, wastage of time and frustration among practitioners. Most of the participants who did not have personal experience with the scheme had heard about these administrative issues from their peers, and cited this as a deterrent to their joining the scheme themselves.

"They are very rigid about the guidelines that we have to follow and not rigid about their part of the guidelines."

-Private practitioner, UP

All the government officials (except one) agreed to the fact that there was need of more transparency in the system related to necessary documents, record keeping and procedures related to reimbursement.

"Majority of the time I think the problem is about the record keeping. Plus it also has to be transparent; he [private practitioner] should not have to run around to get multiple forms. It should be clear and available on the website for everyone to see and the conditions should be clear."

\section{—Senior government official}

\section{Lack of clarity}

In qualifying norms for a private practitioner to get empanelled in government schemes was also referred to as a challenge by government officials. The highly diverse nature of the private sector in India (ranging from a single practitioner running a clinic to superspecialty hospitals) posed a peculiar problem on who should qualify, what are the criteria for empanelment, how these criteria would be implemented, and so on.

"I don't see a very bright future for the private sector in this [accreditation under JSY] until and unless we have a clear cut policy as to how we are going to make them partners."

\section{—District health official, UP}

\section{Trust deficit and unpleasant previous experiences}

Past experiences of participants (private practitioners and government officials) had an influence on how they perceived each other. Thus, in general private healthcare practitioners accused government officials of biased attitude towards them where they, despite having better quality than public sector, were subjected to greater scrutiny and maintenance of documentary proofs. They also referred to government processes as cumbersome, inefficient and unsatisfactory. The government officials felt that private institutions were not transparent with their data and were not interested in maintaining documents and records. Some government officials also felt that private practitioners were primarily oriented towards profits and what benefits they could get and in such a scenario spending time and energy on adequate paperwork and being supervised by the government was something that they disliked.

"On the contrary when we go to a government hospital, what parameters are they maintaining? This is a very partial situation. It's a one sided affair. Standards are very much double."

\section{-Private practitionerr, UP}

The government officials too had their own take on the issue.

"First of all there is a condition of being supervised and we are the ones in the supervisory position and this it not acceptable to them."

\section{-Government official, Jharkhand}

Following from such perceptions, there emerged a phenomenon of trust deficit between private healthcare providers and the government health system that hindered optimal collaboration between the two.

"Mutual faith is not there between the government and the private and that is a major challenge."

-Senior government official

"There is a trust deficit...absolutely and in any transaction whatever it may be if there is a trust deficit that policy is not going to survive, it is never going to survive."

$$
\text { -Private practitioner, UP }
$$

\section{Client-level or patient-level barriers}

The most important patient-level barrier for private practitioners was the poor level of antenatal care among patients who came via the empanelment programmes. This, they said, resulted in complicated cases landing up at literally the last minute in their healthcare facility causing the doctor in charge to arrange for treatments that would not have been required if adequate care had been provided during the antenatal period. A typical example which many participants referred to was women who were severely anaemic who presented themselves at the last minute for the delivery. In such situations, blood had to be arranged and there was no clarity on who would arrange or pay for it. Patients and their caregivers came with the expectation that all services would be provided freely and such situations caused difficulties for all concerned. On the other hand, by virtue of their sustained relationship with their own clients during antenatal care(ANC) period, they seem to have better control over the clinical condition of the client. 
"The patients who come through this system, the JSY, usually they neither have their antenatal check-up, nor have they received any medicines nor have they done any investigations. Now the government has sanctioned very little fund so it is not possible within this fund to manage all of this and see the patient." -Private practitioner, UP

One of the private practitioners referred to the class of patients who come in via JSY and other government programmes and how among some of the private healthcare providers this might be a disincentive since having people from a highly different class could potentially impact the image of their hospital and therefore impact their profit margins. No other private practitioner referred to this issue directly or indirectly as a barrier. This could be possible due to the factor that majority of the private practitioners interviewed for this study were from such cities and towns where such strict demarcation might not exist between the types of patients who come to private hospitals. However, it would be worth investigating if this is a barrier among private practitioners in larger urban centres and how accreditation programmes can be run successfully and equitably in the face of such barriers.

\section{Facility-level barriers}

Government officials pointed out that while several private healthcare providers did provide good quality services, there were an equal numbers who also provide substandard services. Hence for a programme manager, who had to choose from among the applicants to an accreditation programme, this posed a dilemma since private facility did not necessarily equate to high-quality services. Private practitioners admitted that there were institutions that did not provide good quality care but pointed out that this would be the case with any service sector and not just in healthcare system.

"No doubt, some of the hospitals [private hospitals] they are providing good quality services but some of them don't have sterilised OT [operation theatre], don't have specialists and don't have all types of facilities that are needed for quality care. But they are also accredited and giving services."

\section{-District health official, UP}

"It is a challenge for the government because there are all varieties of private settings. So it is not easy to go and expect that the accreditation system will happen overnight. Because if they sincerely do the inspection then most private set ups may not even qualify!"

-Key informant, private

Government officials also pointed out that the differences in charges for services among different types of practitioners also posed challenges for defining a reimbursement rate that is acceptable to all private practitioners. A private practitioner having a large healthcare unit in an urban centre might have a certain rate that was fixed for certain services whereas it would be possible to obtain the same services fromanother private practitioner at much lower rates. This created the dilemma of what would be the ideal rate that the government could reimburse and what sort of practitioners should it look to accredit in its programmes. Should it focus on those whose rates fall within its ambit or should the programme be open to every class of private healthcare institution? The private practitioners quoted a range of 2000-4000 rupees as an acceptable range of reimbursement for a normal delivery and a range of 8000-16 000 rupees for C-section, where for both cases, the higher limit is double the lower limit of expectations, thereby confirming this wide variation in their charges. One solution pointed out by an official was to standardise the rates and procedures across the board in the country. That would mean that whether a normal delivery was conducted in a superspecialty hospital or a clinic, the protocols to be followed would be standard and the amount to be charged for the services would also be fixed. While this would eliminate the problem of differential payments between institutions, given the highly varied nature of healthcare institutions in the country it might not be feasible to implement it across the board.

\section{Facilitators to successful empanelment programmes}

On analysis of the interviews for facilitators of empanelment of private practitioners in government schemes for maternal health, the following themes emerged:

1. system-level changes which can facilitate empanelment of private practitioners,

2. branding: individuals and institutions, and

3. motivation of increasing clientele as well as doing social service.

System-level changes which can facilitate empanelment of private practitioners

Our analysis brought out two system-level changes which could facilitate the empanelment of private practitioners in government services: ease of process and better communication.

\section{Ease of process}

A transparent and easy process that did not overwhelm those who wanted to be part of the programme was considered as an important facilitator by study subjects. Private practitioners shared their experience when even after completing all formalities, they were not sure if they had done everything according to the expectation of the government and if their payments would be processed without any problems. Given that many of the private practitioners are in a comfort zone with patients coming to them and paying for their services, the whole prospect of getting caught up in administrative and legal issues that are time consuming and ambiguous was unattractive. Initiatives such as putting up guidelines on the website, making the entire process of applying to get empanelled, registration, submission of details and payments online 
along with clearly defined timelines for each procedure to be completed were aspects that participants felt would facilitate private involvement in empanelment programmes.

\section{Better communication}

Participants in this study universally acknowledged the trust deficit that existed between the two stakeholders: government and private. Hence they felt that involving all stakeholders in the process right from designing of programme to fixing the rates, protocols, and so on, would go a long way in facilitating open communication between the two stakeholders. They also felt that such involvement should be carried out at all levels between the government and the private sectors from the national level (central government officials, policymakers) right up to the level of service provision.

Some study subjects suggested that one way to achieve this is by involving professional bodies like FOGSI which can act as a bridge between the government and individual private practitioners. In addition to facilitating better communication between the various stakeholders, FOGSI and other similar professional bodies could also be involved in processes right from design of the programme to its implementation and ongoing monitoring.

"They are very important, because professional bodies are the torch bearers of all technical protocols. Plus they can help with their advocacy [for the accreditation scheme]. They can go to every member and they have a wide number of people attached to them. Advocacy and then certification also."

\section{-Senior government official}

\section{Branding: individuals and institutions}

Private practitionerss pointed out that they considered being empanelled by the government to be a positive sign and in some cases even a status symbol that gave them a standing as a place where quality services were delivered. This they felt could be used by the government as an attraction for those who want to get empanelled in their programmes. Also, if those who were part of the government programmes were given a seal of quality, like the ISO (International Organization for Standardization) certification, it would be a motivating factor for signing up for such programmes and provide services even if monetary benefits were minimal or absent.

"If you are recognised by the Government of India it will give you prestige, that itself will attract and on a government seal it will be of quite a value."

\section{-Senior government official}

"A branding system will be rewarding to any hospital. It will inspire the doctor to improve their level, their quality and it is very good."

-Private practitioner, Jharkhand

"The advantage of the brand will be that everybody will think there is something in it and we should not miss out on this opportunity."
—Key informant, private

\section{DISCUSSION}

In this study, we tried to document the major perceived barriers and facilitators for private sector practitioners' participation under the JSY scheme through in-depth interviews with private sector actitioners and key government officials in-charge of PPP in the states of UP and Jharkhand. While both government representatives and private practitionerss expressed keenness in partnering with each other, there were many reported challenges for the same. Based on the perceived challenges and our understanding of the issue, we have also made recommendations for improvement in the system for improved participation of private practitioners in the JSY scheme.

Based on the reported perceptions of participants, our research identified the following major themes: reimbursement amounts currently offered for empanelled practitioners under the JSY schemes are low; there is a widespread trust deficit between government officials and private practitioners; the current system of empanelment of private practitioners under JSY scheme lacks transparency, accountability and clarity on part of various stakeholders; private practitioners have apprehensions about the types of clients who will access services at their institutions after they get empanelled under the JSY scheme; and recognition of empanelled facilities through a quality of care seal or brand is considered an additional motivator by private practitioner for empanelment with JSY scheme.

In our study, both government officials and private practitioners felt that the current reimbursements for delivery services offered under JSY schemes were very low. A study on practitioners' perceptions on empanelment under CY also reported that reimbursement amounts were considered low by private practitioners ${ }^{30}$; however, there were considerable differences from our findings. In CY, the rates provided are higher (INR 2800) than those provided under JSY (INR 1400). In the CY study, the practitioners had variable responses to the adequateness of this amount (rural participants said the amounts were sufficient for normal deliveries), whereas in our study the practitioners unanimously said the amounts were very low. This might be due to three major reasons-higher amounts offered under CY, primarily urban nature of our private practitioners who routinely charge higher for services, and the time difference between two studies leading to increased costs of care. A study in Maharashtra found that amounts offered under JSY were low even for contracting out just the services of obstetricians for providing care in public facilities. ${ }^{6}$ A unique finding of our study was the perspective of government officials who also considered these amounts significantly lower than what will be appropriate, but reported that any revision in reimbursement amounts was out of scope of their administrative authority. Our findings in comparison to this study suggest that if the government system intends to 
engage well-performing private facilities to share burden of tertiary centres and leverage their specialist presence, the amounts reimbursed under the schemes will have to be substantially (three to four times) increased and such process will require a policy change at national level.

Similar to our study, the study on CY also concluded that mistrust between private and public sectors was an important reason for private practitioners' disinterest in partnering with the scheme. ${ }^{30}$ This mistrust was fuelled primarily by previous experiences of private practitioners like difficulty in getting empanelled or getting their reimbursements. A study on private practitioners' perspectives on participation in RSBY scheme also reported tension between the insurance company and doctors over delays, malpractices, perceived threat of being de-empanelled and moral hazards. ${ }^{31}$ However, our study brings out a very important perspective of government officials on this mistrust. The government officials perceived that private practitioners were mostly concerned with making profit with services and thus cut corners with quality of services. Another challenge perceived by government officials was the hesitation of the private institutions in maintaining records and agreeing to have their quality of services supervised by them.

There was a high level of dissatisfaction among private practitioners with the system for application for empanelment and providing services under it. For applications, there was a reported lack of transparency in terms of response times, criteria for empanelment and the process of implementation. The practitioners also perceived that government officials were extremely rigid with respect to the implementation of guidelines. Procedural burden and paperwork were also reported as a perceived challenge by the CY study from Gujarat. ${ }^{30}$ In our study, another frequently reported challenge was the delay in the payment of reimbursement amounts. Delayed availability of funds at the point of disbursal from higher levels was reported as one reason for delayed reimbursements by government officials. This is consistent with the findings of an evaluation of JSY scheme where timely availability of funds was quoted as a major challenge by government officials. ${ }^{5}$ Although in a study from Maharashtra, block and higher level administrators did not perceive any problems with the fund flow, ${ }^{6}$ similar procedural, administrative and transparency-related challenges have been reported from other PPP initiatives in India and other nearby countries. ${ }^{31-34}$ Thus, procedural delays, fund availability and administrative processes will need to be improved for accreditation and empanelment of private facilities under JSY programme to improve.

Another unique finding of our study was that despite the challenges prevalent in the system, most private sector practitioners said that their interest in partnering with the government system will improve if there is a recognition of partnering institutions by the way of a brand or seal apart from the usual reimbursements for services rendered. This seal or brand could be based on the process of verification of services at these institutions at the time of application. Thus, this recommended action seems to partially have the potential to offset some of the barriers experienced by practitioners for partnering with the system. This seems very well in line with the expressed motivation of practitioners that partnering with the system will bring them more clients and will increase revenues. Any recognition of services of these institutions that they can advertise will increase the visibility of institution in the sector and will, in turn, bring more clients to the institutions. Apart from economic benefits, the recognition of services was expected to lead to improved professional standing and satisfaction of these partnering private sector practitioners. Formal accreditation of facilities and sense of professional satisfaction from services have been reported as an influencer of success partnerships in other settings as well. ${ }^{35}$

Similar to the CY study in Gujarat, private practitioners in our study also reported concerns with the type of clients accessing services. However, in our study, the predominant concern was the perceived poor ANC status of clients targeted under JSY. Only one private practitioner expressed apprehension that the category of clients accessing services at their centres under the JSY scheme will lead to a 'downgrading' of the image of their centres whereas this was commonly reported by the CY study participants. ${ }^{30}$

Our major recommendations from this study that might be beneficial in improving the PPPs under the JSY and other related schemes are the following:

First, the reimbursement under JSY scheme should be increased significantly taking into account the current cost of services. Payment rates for similar services under the schemes such as Central Government Health Services are significantly higher than the current JSY rates. These examples can form a basis for cost calculations to arrive at appropriate reimbursement rates under JSY schemes. Second, the existing guidelines defining the process, target beneficiaries, criteria for selection of private practitioners and service standards should be reviewed and refined to ensure a better fit with the current context. For this purpose, all the important stakeholders including representatives from professional associations should be consulted. The revised guidelines should also strongly focus on setting up systems for periodic reviews and refinements in the structure of the system. Furthermore, the guidelines should bring a strong impetus on improving the transparency and accountability in the system for application, empanelment and reimbursements for services under JSY scheme. Use of technology for creating online systems for such activities should also be procured. This will help in both improving transparency in the system and reducing paperwork and related administrative challenges. Deidentified data such as payments, services provided, antenatal care status, medications, number of C-sections, patient income levels, and so on can be periodically published on publicly accessible websites to strengthen accountability.

Leveraging existing identification systems such as Aadhaar numbers for public health has been suggested 
widely. ${ }^{36}$ The same can be used to effectively and efficiently track the target beneficiaries. Third, communication with stakeholders regarding the features of PPP mechanism under the JSY scheme should be improved from the government's side. This should include clear instructions to the government officials regarding the operational aspects of guidelines on empanelling private practitioners under JSY scheme, their sensitisation on important features at available opportunities, and regular oversight from the government of India and state government's side. Practitioners should be educated better on the entitlements under the schemes, administrative processes and target beneficiaries through targeted communication efforts using mass media tools. Professional associations of providers should be involved in disseminating this information further to the private sector practitioners. Their help can also be taken for defining the role of private sector more clearly in the delivery of maternal and newborn health services under the ambit of JSY scheme. Finally, the government should consider strategies to establish partnership under the scheme as a desirable and prestigious action. This can be promoted through developing a branding strategy for the scheme and creating public awareness about the scheme. This will also include developing a seal of services that can be awarded to the partnering institution that can advertise their coveted status as a partner in government's effort for improving quality of services in the country.

\section{CONCLUSION}

We conclude by saying that the private sector can potentially play an important complementary role to the public sector for maternity services in India. Despite provisions in existing schemes, due challenges such as inadequate reimbursements, mistrust between the stakeholders, lack of clarity regarding processes, administrative delays, lack of transparency and ease in the process of empanelment of private sector, it is severely underutilised. This can be improved by improving the system of empanelment of private sector to address challenges including relook at the reimbursement amounts, improving communication with the private sector, and by introducing strategies to ensure that partnership with public system is seen as a prestigious thing by private sector.

Acknowledgements We are most grateful and extend our sincere thanks to all people who participated in this study. We would like to thank our internal reviewers - Linda Fogarty, Peter Johnson and Adrienne Kols—-for their support in drafting the manuscript. We would also like to acknowledge the Maternal and Newborn Health team of Jhpiego, India, for their support in conducting this study. We thank our funder for their continued support. The research in this publication was supported by funding from MSD through its MSD for Mothers programme. MSD had no role in the design, collection, analysis and interpretation of data, in writing of the manuscript, or in decision to submit the manuscript for publication. The content of this publication is solely the responsibility of the authors and does not represent the official views of MSD. MSD for Mothers is an initiative of Merck \& Co. Inc. Kenilworth, NJ, USA.

Contributors VY, SK, SBS and BS developed the concept and designed the research. VY, SK, SBS, AS and SB were involved in conducting the in-depth interview. AS, SBS and GAS were involved in data analysis and interpretation. VY,
SK, SBS, AS, SP, PM and DS drafted the manuscript. VY, SK and SBS had critically reviewed the manuscript. All authors read and approved the final manuscript.

Funding This work was supported with funding from MSD through its MSD for Mothers programme (Grant No. MFM-130508-010145). The webpage for MSD for Mothers is http://www.msdformothers.com/

\section{Competing interests None declared.}

Ethics approval Institutional Review Boards (IRB) of International Institute of Health Management Research (IIHMR), India, and Johns Hopkins Bloomberg School of Public Health, USA.

Provenance and peer review Not commissioned; externally peer reviewed.

Data sharing statement Data are available from Jhpiego's internal institutional data access committee for researchers who meet the criteria for access to confidential data. Data consist of recorded interviews and have identifiers. Corresponding author can be contacted for further communication.

Open Access This is an Open Access article distributed in accordance with the Creative Commons Attribution Non Commercial (CC BY-NC 4.0) license, which permits others to distribute, remix, adapt, build upon this work non-commercially, and license their derivative works on different terms, provided the original work is properly cited and the use is non-commercial. See: http://creativecommons.org/ licenses/by-nc/4.0/

(c) Article author(s) (or their employer(s) unless otherwise stated in the text of the article) 2017. All rights reserved. No commercial use is permitted unless otherwise expressly granted.

\section{REFERENCES}

1. Rao M, Rao KD, Kumar AKS, et al. Human resources for health in India. The Lancet 2011;377:587-98.

2. Balasubramaniam $P$, Bartlett $H$, Yadav V, et al. Universal Health Care Systems Worldwide: 16 International Case Studies;. in High Level Expert Group Report on Universal Health Coverage for India [Internet] 2011 http://planningcommission.nic.in/reports/genrep/rep_uhc0812. pdf.

3. Key Indicators of Social Consumption in India Health [Internet]. National Sample Survey Office; Ministry of Statistics and Program Implementation 2015 http://mospi.nic.in/Mospi_New/upload/nss_ 71st_ki_health_30june15.pdf.

4. Yojana JS. Features and frequently asked questions and answers [Internet] http://164.100.130.11:8091/rch/JSY_guidelines_2006_ along with faq.pdf.

5. Zodpey S, Paul VK. P. AlIMS, and SC- State of India's Newborns (SOIN) 2014- a report. Internet]. Public Health Foundation of India, All India Institute of Medical Sciences and Save the Children. New Delhi, India 2014 http://www.newbornwhocc.org/SOIN_PRINTED\%20149-2014.pdf.

6. Chaturvedi S, Randive B. Public private partnerships for emergency obstetric care: lessons from Maharashtra. Indian Journal of Community Medicine 2011;36:21-6.

7. Policy NH. [Internet]. Ministry of Health \& Family Welfare, Government of India 2002 https://childlineindia.org.in/CP-CRDownloads/National_Health_policy_2002.pdf.

8. Policy NH. Ministry of Health and Family Welfare [Internet]. 2017 http://www.thehinducentre.com/multimedia/archive/03145/National_ Health Po 3145484a.pdf

9. Bhat R, Mavalankar DV, Singh PV, et al. Maternal Healthcare financing: gujarat's Chiranjeevi Scheme and Its Beneficiaries. $J$ Health Popul Nutr 2009;27:249-58.

10. Singh A, Mavalankar DV, Bhat R, et al. Providing skilled birth attendants and emergency obstetric care to the poor through partnership with private sector obstetricians in Gujarat, India. Bull World Health Organ 2009;87:960-4.

11. Government of Delhi -4.Plan Schemes - Poor.doc - plan Schemes. pdf [Internet]. http://delhiplanning.nic.in/Reports/plan\%20Schemes. pdf (cited 2016 Dec 8).

12. WHO l effect of Chiranjeevi Yojana on institutional deliveries and neonatal and maternal outcomes in Gujarat, India: a difference-indifferences analysis [Internet]. WHO. http://www.who.int/bulletin/ volumes/92/3/13-124644/en/ (cited 2016 Dec 8).

13. Concurrent assessment of Janani Suraksha Yojana (JSY) scheme in selected states of India, 2008 [Internet]. Ministry of Health and Family Welfare India/ UNFPA 2009 http://india.unfpa.org/publications/ concurrent-assessment-janani-suraksha-yojana-jsy-selected-states

14. Nandan D. Evaluation of MAMTA Scheme in National Capital Territory of Delhi [Internet]. Department of Planning \& Evaluation 
National Institute of Health and Family Welfare New Delhi 2010 http:// citeseerx.ist.psu.edu/viewdoc/download?doi=10.1.1.464.7100\&rep= rep1\&type=pdf.

15. Ravindran TS. Public-private partnerships in maternal health services. Economic \& Political Weekly 2011;46:43 http://www. indiaenvironmentportal.org.in/files/file/Maternal\%20Health\% 20Services.pdf.

16. Quarterly NRHM MIS report (Status as on 31.03.2016) Governnment of India [Internet]. [cited 2016 Dec 8]. Available from: http://nrhm.gov.in/nhm.html?id=405

17. Health Management Information System, A digital initiative under National Health Mission, Ministry of Health \& Family Welfare, Government of India [Internet]. [cited 2016 Dec 26]. Available from:https://nrhmmis.nic.in/SitePages/Home.aspx

18. Lim SS, Dandona L, Hoisington JA, et al. India's Janani Suraksha Yojana, a conditional cash transfer programme to increase births in health facilities: an impact evaluation. The Lancet 2010;375:2009-23.

19. Hogan MC, Foreman KJ, Naghavi M, et al. Maternal mortality for 181 countries, 1980-2008: a systematic analysis of progress towards Millennium Development Goal 5. The Lancet 2010;375:1609-23.

20. Rajaratnam JK, Marcus JR, Flaxman AD, et al. Neonatal, postneonatal, childhood, and under-5 mortality for 187 countries, 1970-2010: a systematic analysis of progress towards Millennium Development Goal 4. The Lancet 2010;375:1988-2008.

21. UN. The Millennium Development Goals report 2011 [Internet]. United Nations, New York 2011 http://www.un.org/millenniumgoals/ pdf/\%282011_E\%29\%20MDG\%20Report\%202011_Book\%20LR. pdf (cited 2012 Jun 18).

22. Randive B, Diwan V, De Costa A. India's Conditional Cash Transfer Programme (the JSY) to Promote Institutional Birth: Is There an Association between Institutional Birth Proportion and Maternal Mortality? PLoS One 2013;8:e67452.

23. Challenges constraining access to insulin in the private-sector market of Delhi, India | BMJ Global Health [Internet]. http://gh.bmj. com/content/1/3/e000112.article-info (cited 2016 Dec 23).

24. BMJ Blogs: the BMJ » Blog Archive " Madhukar Pai: New insights into the tuberculosis problem in India's private sector [Internet]. http://blogs.bmj.com/bmj/2016/08/26/madhukar-pai-new-insightson-tuberculosis-problem-in-indias-private-sector/ (cited 2016 Dec 23).
25. Sharma A, Kaplan WA, Chokshi M, et al. Role of the private sector in vaccination service delivery in India: evidence from private-sector vaccine sales data,2009-12. Health Policy Plan 2016:czw008.

26. Janani-Shishu Suraksha Karyakram - Governnment of India [Internet]. http://nrhm.gov.in/janani-shishu-suraksha-karyakram.html (cited 2016 Dec 8).

27. Nagpal J, Sachdeva A, Sengupta Dhar R, et al. Widespread non-adherence to evidence-based maternity care guidelines: a population-based cluster randomised household survey. BJOG Int J Obstet Gynaecol 2014.

28. Bhate-Deosthali P, Khatri R, Wagle S. Poor standards of care in small, private hospitals in Maharashtra, India: implications for publicprivate partnerships for maternity care. Reprod Health Matters 2011;19:32-41.

29. Rashtriya Swasthya Bima Yojana [Internet]. http://www.rsby.gov.in/ about_rsby.aspx (cited 2016 Dec 26).

30. Ganguly P, Jehan K, de Costa A, et al. Considerations of private sector obstetricians on participation in the state led "Chiranjeevi Yojana" scheme to promote institutional delivery in Gujarat, India: a qualitative study. BMC Pregnancy Childbirth 2014:14:352.

31. Trivedi M, Saxena DB. Third Angle of RSBY: service Providers' Perspective to RSBY-operational Issues in Gujarat. J Fam Med Prim Care 2013;2:169-72.

32. Khetrapal, $\mathrm{S}$ (2016) Public-Private Partnerships in the Health Sector The Case of a National Health Insurance Scheme in India. $\mathrm{PhD}$ thesis, London School of Hygiene \& Tropical Medicine. DOI: 10.17037/PUBS.03141184.

33. Chakravarty N, Sadhu G, Bhattacharjee S, et al. Mapping privatepublic-partnership in health organizations: india experience. Int $J$ Med Public Health 2015;5:128-32.

34. Jehan K, Sidney K, Smith $\mathrm{H}$, et al. Improving access to maternity services: an overview of cash transfer and voucher schemes in South Asia. Reprod Health Matters 2012;20:142-54.

35. Braithwaite J, Greenfield D, Westbrook J, et al. Health service accreditation as a predictor of clinical and organisational performance: a blinded, random, stratified study. Quality and Safety in Health Care 2010;19:14-21.

36. Mishra SR, Sharma A, Kaplan WA, et al. Liberating data to combat NCDs. Lancet Diabetes Endocrinol 2016;4:482-3. 